\title{
Editorial
}

\section{Gesunde Ernährung - was ist das?}

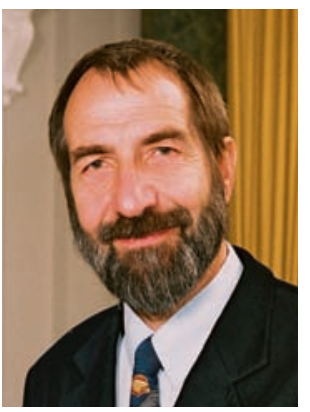

Gesundheit gilt als hohes Gut. Jedermann möchte ein langes Leben genießen, frei von Sorgen und körperlichen Gebrechen. Seit mehr als einem halben Jahrhundert müht sich der Sozialstaat, dazu die notwendigen Voraussetzungen zu schaffen. Zunehmend wachsen die erforderlichen Aufwendungen und stoßen an die Grenzen des Leistbaren. Dennoch halten Politiker unverdrossen die Fahne hoch, die uns auf dem Weg ins fröhliche und unbeschwerte Altwerden voranflattern soll. Zu leicht könnte man stolpern, wenn man sich in dieser Debatte unliebsamer Argumente bedient.

Nicht anders verhält sich die Lebensmittelindustrie. Ihre bunten Werbebanner versprechen risikofreien Genuss all ihrer Produkte. Darin vermählen sich stereotype Vokabeln wie „viel Milch“, "naturrein“, „das Beste vom Obst“" mit farbenfrohen Bildern traumschöner Landschaften, lachender Kinder und putzmunterer Senioren. Demnach ließe sich körperliche Intaktheit im Supermarkt kaufen.

Dennoch zweifelt der Verbraucher. Er misstraut den blumigen Verheißungen der Industrie. Auch der erhobene Zeigefinger der Ernährungswissenschaft: „Nie waren unsere Lebensmittel sicherer als heute!" weist ihm keine glaubhafte Richtung. Ihn verstören Lebensmittelskandale, die scheinbar überhandnehmen und durch Überreaktion der
Medien zu krankmachenden Monstern aufgeblasen werden. Und so wäre es vielen am liebsten, sie könnten auf Großmutters Wintervorräte zugreifen oder auf ihr würziges, mürbes Brot, selbst wenn man einige angeschimmelte Partien wegschneiden müsste.

Nun hat es der Verbraucher auch nicht einfach. Wie kann er sich orientieren in einem Feld, das ihm nicht allein das gesunde Überleben garantieren, sondern vielmehr Freude und Genuss verschaffen soll? Von allen Seiten stürzen Ratschläge auf ihn ein: Eigne Dir Ernährungswissen an! Lies die Verpackungsinformation! Glaube nicht, was Dir leichthin versprochen wird! Folgt er solchen Empfehlungen, dann entmutigt ihn rasch die überbordende Informationsflut, mit der inn traditionelle Medien und Internet überschwemmen.

Unsere Aufgabe in der Ernährungsberatung ist, den Verbraucher kurz und verständlich aufzuklären. Wir wissen: Die gesunde Ernährung gibt es nicht. Aus der Vielfalt möglicher Wege greift das vorliegende Heft einige der vorrangigen Themen auf und vermittelt praktikable Ratschläge, mit denen wir die Entscheidungskompetenz des Verbrauchers erhöhen können.

Prof. Dr. Hans-Joachim F. Zunft 